\title{
Análise da intensidade de fluorescência em diferentes compósitos após exposição a agentes clareadores caseiros à base de peróxido de carbamida em diferentes concentrações
}

\section{Analysis of fluorescence intensity in different composites after exposure to different concentrations of carbamide peroxide home bleaching agents}

Mariana De Carlo Bello* Vanessa Aozani**

Renata Plá Rizzolo Bueno***

Raquel Pachaly

Marcos Antônio Villetti****

Roselaine Terezinha Pozzobon*

\section{Resumo}

Objetivo: o objetivo neste estudo foi avaliar a influência de agentes clareadores à base de peróxido de carbamida (PC), em diferentes concentrações, sobre a fluorescência de três compósitos. Métodos: foram confeccionados 27 corpos de prova divididos em 9 grupos $(n=3)$, que foram armazenados em água deionizada, expostos ao PC $10 \%$ por 6 horas diárias e PC $22 \%$ por 1 hora diária, durante 14 dias. Após, foi realizada a leitura da fluorescência em um espectrofotômetro. Os valores de intensidade de fluorescência obtidos foram submetidos aos testes Shapiro-Wilk, Levene e Games-Howell $(p<0,05)$. Resultados: a média dos valores de intensidade de fluorescência para os grupos controle dos compósitos Esthet-X e Opallis não apresentou diferença estatisticamente significativa. Entretanto, o compósito Charisma apresentou intensidade de fluorescência estatisticamente diferente da dos demais. Após serem expostas aos diferentes agentes clareadores, apenas $O$ compósito Charisma exposto ao PC 22\% apresentou al- terações estatisticamente significativas, aumentando a fluorescência. Conclusão: a intensidade de fluorescência pode ser afetada pela ação de agentes clareadores à base de $P C$, dependendo de sua concentração e das características do compósito.

Palavras-chave: Resina composta. Fluorescência. Clareadores.

Graduada pela Universidade Federal de Santa Maria, especialista em Endodontia pela Uningá, Santa Maria-RS, Brasil. Mestra em Ciências Odontológicas, Universidade Federal de Santa Maria, Santa Maria, RS, Brasil.

Graduada pela Universidade Federal de Santa Maria, Santa Maria-RS, Brasil.

Mestra em Ciências Odontológicas pela Universidade Federal de Santa Maria, Santa Maria-RS, Brasil.
Prof. Dr. do Departamento de Física da Universidade Federal de Santa Maria, Santa Maria-RS, Brasil.

Professora Doutora da disciplina de Dentística, Departamento de Odontologia Restauradora da Universidade Federal de Santa Maria, Santa Maria-RS, Brasil. 


\section{Introdução}

O crescente interesse dos pacientes por uma melhor aparência do sorriso, associado ao desenvolvimento significativo de novos materiais e técnicas, incentivados, por sua vez, pela divulgação da mídia sobre conceitos de estética, proporcionaram uma evolução importante da odontologia estética ${ }^{1,2}$.

Atualmente, novos materiais e técnicas restauradoras são constantemente desenvolvidos para atender às exigências estéticas dos profissionais e dos pacientes ${ }^{2}$. Essas evoluções objetivam reproduzir as propriedades óticas dos dentes humanos, confeccionando restaurações cada vez mais semelhantes ao dente natural, de modo a conferir-lhes naturalidade e luminosidade ${ }^{3-5}$.

Entretanto, para que as restaurações alcancem excelência estética e funcional, é fundamental que o profissional conheça as propriedades óticas tanto dos dentes como dos materiais restauradores, para que possa reproduzir com detalhes as estruturas dentais perdidas. $\mathrm{O}$ comportamento ótico dos materiais deve ser compatível com a estrutura natural do dente. No caso dos compósitos, o formato, o tipo, o tamanho e a concentração das partículas de carga das diferentes marcas comerciais, assim como a adição de monômeros e pigmentos ${ }^{6-10}$ são fatores responsáveis pelas características de dispersão ótica dos materiais na tentativa de imitar as propriedades óticas dos tecidos dentais com relação à fluorescência, translucidez e opacidade ${ }^{8,11}$.

A dentição natural também apresenta a capacidade de absorver e refletir a energia luminosa. Quando o espectro da energia luminosa é absorvido no comprimento de onda abaixo daquele determinado para a luz visível, a estrutura dental é capaz de alterar o comprimento de onda para 0 espectro dentro da faixa do visível e, dessa forma, emitir uma luz branco-azulada ${ }^{2,5,12}$. Esse fenômeno caracteriza-se como fluorescência, que é uma forma de fotoluminescência na qual a energia radiante ultravioleta (UV) é absorvida por um objeto que, posteriormente, emite energia luminosa dentro do espectro visível azulado ${ }^{3,12,13}$ e está mais presente na dentina do que no esmalte, devido à maior quantidade de matéria orgânica fotossensível ao baixo comprimento de onda ${ }^{5}$. Essa característica potencializa a naturalidade dos dentes, levando a que pareçam mais brancos, claros e brilhantes ${ }^{13-16}$. Essa luminosidade vai se alterando no decorrer do dia. Durante a noite, as pessoas também ficam expostas a ambientes iluminados por lâmpadas que emitem o comprimento de onda dentro da faixa em que ocorre o fenômeno ${ }^{17-19}$.

A reprodução dessa propriedade, embora não seja determinante na obtenção do sucesso funcional restaurador, pode ser de imensa relevância para dentes de indivíduos que participam de atividades que os exponham a diferentes fontes luminosas, incluindo luz UV ${ }^{3-6}$. Restaurações não fluorescentes destoam do tecido natural e parecem mais evidentes sob iluminação que contém luz UV, criando efeitos indesejados ${ }^{3-5}$. Sob luz negra, as restaurações realizadas com compósitos não fluorescentes aparecem com manchas negras ${ }^{20}$. Se o comportamento do material restaurador for diferente do dente natural, o resultado estético pode ser prejudicado em maior ou menor intensidade, dependendo do local onde o paciente se encontrar ${ }^{17,18}$. Para tentar resolver o problema, os fabricantes adicionaram ao material agentes luminóforos como o urópio, térbio, itérbio e cério ${ }^{20,21-23}$. A incorporação desses pigmentos tem reproduzido satisfatoriamente a fluorescência dos dentes naturais para alguns compósitos ${ }^{24}$.

A alteração de cor dos dentes é um aspecto que prejudica significantemente o sorriso, e há uma valorização cada vez maior dos procedimentos menos invasivos ${ }^{25,26}$.

As técnicas de clareamento dental representam uma opção importante de tratamento estético ${ }^{27,28}$ e baseiam-se na aplicação de agentes químicos que, por uma reação de oxidação, removem pigmentos orgânicos dos dentes ${ }^{29,30}$. Os agentes clareadores à base de peróxido de carbamida são constituídos de peróxido de hidrogênio unidos a ureia, estando disponíveis em diferentes concentrações, o que facilita sua aplicação em diferentes protocolos de tratamento $^{31,32}$.

Compósitos são constantemente expostos a diversos agentes externos físicos e químicos, que podem mudar suas propriedades óticas ${ }^{4,14,33}$. Com relação aos agentes clareadores, existem diversos estudos que, ao avaliarem a sua ação sobre materiais restauradores estéticos, relatam alterações em diferentes níveis ${ }^{34-38}$. Dessa forma, a proposta do presente estudo foi investigar possíveis alterações na fluorescência de compósitos após exposição a agentes clareadores à base de peróxido de carbamida.

\section{Métodos}

Para a realização deste estudo, foram utilizados três compósitos das marcas comerciais Charisma ${ }^{\circledR}$ (Heraeus Kulzer, Hanau, Alemanha), Esthet-X ${ }^{\circledR}$ (Dentsply, Petrópolis, Rio de Janeiro, Brasil) e Opallis $^{\circledR}$ (FGM Produtos Odontológicos, Joinvile, Santa Catarina, Brasil), na cor universal A2, e dois agentes clareadores à base de peróxido de carbamida nas concentrações de $10 \%$ e $22 \%$ (Whiteness $^{\circledR}$ - FGM Produtos Odontológicos, Joinvile, Santa Catarina, Brasil). No total, foram confeccionados 27 corpos de prova circulares divididos em 9 grupos (n = 3) (Quadro 1), utilizando uma matriz acrílica bipartida com $2 \mathrm{~mm}$ de espessura e perfuração central circular de $10 \mathrm{~mm}$ de diâmetro que foi posicionada sobre uma placa de vidro. O compósito foi 
inserido no interior da perfuração central até o total preenchimento do orifício. Sobre o compósito foi posicionada uma matriz de poliéster para impedir que o corpo de prova aderisse à placa de vidro durante seu processo de polimerização e, sobreposta a esta, uma segunda placa de vidro foi posicionada e comprimida para que houvesse escoamento do excesso de material. Para a fotopolimerização, foi utilizado um fotopolimerizador com luz halógena (Dabi Atlante ${ }^{\circledR}$, Ribeirão Preto, São Paulo, Brasil) com potência de $600 \mathrm{~mW} / \mathrm{cm}^{2}$, que foi testado previamente por meio de um radiômetro (Gnatus ${ }^{\circledR}$, Ribeirão Preto, São Paulo, Brasil). A primeira fotopolimerização foi realizada sobre a placa de vidro e a segunda, diretamente sobre o compósito, ambas durante 20 segundos. Após a confecção, os corpos de prova foram armazenados em potes individuais devidamente identificados contendo água deionizada e levados à estufa a $37^{\circ} \mathrm{C}$ por 24 horas. Decorrido esse período, todos os corpos de prova foram polidos com auxílio de uma pinça em politriz APL- $4^{\circledR}$ (Arotec S.A. Indústria e Comércio, São Paulo, Brasil), com a sequência de lixas d'água de granulação 600 , 1200, 2500, durante 10 segundos em cada lixa. Em seguida, as amostras retornavam para os potes com água deionizada em estufa, até o momento de serem expostas à ação dos agentes clareadores.

Os corpos de prova do grupo controle (grupos $1,4,7)$ foram armazenados somente em água deionizada. Já os grupos 2, 5 e 8 foram submetidos ao tratamento clareador com peróxido de carbamida $10 \%$ por 6 horas diárias durante 14 dias. Por fim, os grupos 3, 6 e 9 foram submetidos ao tratamento clareador com peróxido de carbamida $22 \%$ por 1 hora diária, também durante 14 dias, para simular um protocolo de tratamento clareador caseiro. Enquanto não estavam sendo clareadas, as amostras ficaram armazenadas em água deionizada a $37^{\circ} \mathrm{C}$. Ao final dos 14 dias, foi realizada a leitura da fluorescência.

A fluorescência emitida foi registrada por um aparelho denominado espectrofotômetro Cary Eclipse $^{\circledR}$ de fluorescência ${ }^{16,20,22,23}$ (Varian Agilent Technologies, Santa Clara, Califórnia, EUA). O equipamento mede a fluorescência de corpos sólidos e líquidos numa faixa de comprimento de onda que vai de $200 \mathrm{~nm}$ a $1100 \mathrm{~nm}$. A câmara interna desse aparelho é composta por: base experimental, fenda (slit) do raio excitador e fenda do raio receptor. A base experimental é composta por três estruturas: êmbolo fixador, espaço para fixação do porta-espécime e barreira protetora.

Para realização do teste, o porta-espécime foi acoplado à base experimental do espectrofotômetro de fluorescência. Uma vez colocado nessa base, o corpo de prova foi imobilizado por um êmbolo que não permitia qualquer movimento do conjunto durante os testes.
Previamente à fase experimental, o espectrofotômetro de fluorescência foi calibrado. Por meio da leitura de um corpo de prova de cada um dos compósitos avaliados, para determinar o seu comprimento de onda de luz UV incidente e a fenda de abertura do raio excitador e do raio receptor de luz emitida, o espectro de emissão das amostras foi medido de 350 a $600 \mathrm{~nm}$.

Com os corpos de prova em posição na base experimental, os testes foram iniciados pelo computador. Qualquer possibilidade de fluorescência, por menor que fosse, foi registrada pelo aparelho.

$\mathrm{O}$ registro dos valores obtidos foi visualizado mediante uma curva de intensidade de fluorescência (ordenada) versus comprimento de onda (abscissa). Dessa maneira, foi possível determinar, para o compósito estudado, a respectiva fluorescência, identificando seu comprimento de onda e a intensidade de luz emitida.

A média dos valores de intensidade de fluorescência foi submetida aos testes de Shapiro-Wilk, Levene e Games-Howell com nível de significância de $5 \%$.

\begin{tabular}{|c|c|}
\hline Grupos & Situação experimental \\
\hline Grupo $1(n=3)$ & Charisma ${ }^{\circledR} / a ́ g u a$ deionizada \\
\hline Grupo $2(n=3)$ & Charisma $^{\circledast} /$ peróxido carbamida $10 \%$ \\
\hline Grupo $3(n=3)$ & Charisma ${ }^{\circledR} /$ peróxido carbamida $22 \%$ \\
\hline Grupo $4(n=3)$ & Esthet- $X^{\circledast} /$ água deionizada \\
\hline Grupo $5(n=3)$ & Esthet- $X^{\circledast} /$ peróxido carbamida $10 \%$ \\
\hline Grupo $6(n=3)$ & Esthet- $X^{\circledR} /$ peróxido carbamida $22 \%$ \\
\hline Grupo $7(n=3)$ & 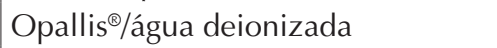 \\
\hline Grupo $8(n=3)$ & Opallis ${ }^{\circledast} /$ peróxido carbamida $10 \%$ \\
\hline Grupo $9(n=3)$ & Opallis ${ }^{\circledast} /$ peróxido carbamida $22 \%$ \\
\hline
\end{tabular}

Quadro 1 - Distribuição dos grupos nas diferentes situações experimentais avaliadas

\section{Resultados}

A média dos valores de intensidade de fluorescência dos diferentes grupos experimentais está expressa na Tabela 1. Para os grupos controle, somente o compósito Charisma apresentou diferença estatisticamente significativa para os valores de intensidade de fluorescência, quando comparados aos compósitos Esthet-X e Opallis. Quando se comparou o grupo controle com os grupos tratados com agentes clareadores à base de $\mathrm{PC}$ para cada compósito, observou-se que não existiu diferença estatisticamente significativa tanto para Esthet-X quanto para Opallis. Já para Charisma, o valor de intensidade de fluorescência após o tratamento com PC $22 \%$ aumentou, diferentemente do que ocorreu com o grupo tratado com PC $10 \%$ e com o grupo controle, que não apresentaram diferença estatisticamente significativa entre si. 
Tabela 1 - Média (dp) dos valores de intensidade de fluorescência nos diferentes grupos experimentais

\begin{tabular}{l|c|c|c}
\cline { 2 - 3 } \multicolumn{1}{c|}{} & Esthet- $X^{\circledR}$ & Opallis $^{\circledR}$ & Charisma $^{\circledR}$ \\
\hline Controle & $175,34(31,54) \mathrm{Aa}$ & $622,37(151,86) \mathrm{Aa}$ & $47,72(1,22) \mathrm{Bb}$ \\
Carbamida 10\% & $170,12(66,07) \mathrm{Aa}$ & $494,29(242,79) \mathrm{Aa}$ & $35,43(15,08) \mathrm{Bb}$ \\
Carbamida 22\% & $234,44(34,27) \mathrm{Aa}$ & $508,63(181,65) \mathrm{Aa}$ & $77,85(12,74) \mathrm{Ba}$ \\
\hline
\end{tabular}

Para cada linha, os valores com letras maiúsculas diferentes indicam diferença estatisticamente significativa $(p<0,05)$.

Para cada coluna, os valores com letras minúsculas diferentes indicam diferença significativa $(p<0,05)$.

\section{Discussão}

A fluorescência é uma característica que confere naturalidade aos dentes ${ }^{13-16}$. Sendo essa uma característica importante, é de esperar que os materiais restauradores apresentem comportamento semelhante ao dente natural ${ }^{3-5}$. Se o comportamento do material restaurador for diferente do dente natural, o resultado estético pode ser prejudicado em maior ou menor intensidade, dependendo do local onde $o$ paciente se encontra, pois os raios ultravioletas são encontrados em diversos locais ${ }^{3,13,19}$. Alguns autores relatam que existe uma considerável variação de intensidade de fluorescência comparando diferentes compósitos ${ }^{3,5,6,39,40}$. Enquanto algumas marcas apresentaram pouca ou nenhuma fluorescência, outras apresentaram resultado próximo ao do dente e, ainda, alguns compósitos apresentaram intensidade de fluorescência superior ao dente natural. Os resultados deste estudo para o grupo controle foram similares, pois se constatou que a intensidade da fluorescência do compósito Charisma apresentou diferença estatisticamente significativa quando comparada aos compósitos Esthet-X e Opallis.

É possível que o comportamento diferente da Charisma em relação aos outros compósitos deva-se às características de composição do material (matriz orgânica, carga inorgânica, pigmentos, agentes fluorescentes, entre outros), pois possuem efeito intenso nas características de fluorescência e transmitância direta ${ }^{6-10}$. Outro fator que pode ter influenciado os resultados obtidos é alguma variação individual dos compósitos utilizados, pois enquanto a Esthet-X e a Opallis apresentam compósitos para esmalte e para dentina separadamente, a Charisma não possui essa especificação, ou seja, o mesmo compósito é utilizado para simular tanto o esmalte quanto a dentina. Esses diferentes sistemas restauradores podem justificar os resultados, na medida em que a Charisma foi a que apresentou maior variabilidade de comportamento quando comparada com a Esthet-X e a Opallis.

Os agentes clareadores são agentes químicos que afetam diversas propriedades dos compósitos, como a rugosidade ${ }^{33-38}$, a cor $^{33}$ e a translucidez ${ }^{7}$. Nos resultados deste estudo, observou-se que os compósitos Esthet-X e Opallis não sofreram alterações significativas quando tratados com PC a 10 ou $22 \%$. Porém, a Charisma, quando submetida ao PC $22 \%$, aumentou a fluorescência. Essa diferença pode ter ocorrido por se tratar de um agente clareador mais concentrado, o que poderia ter afetado a fluorescência por modificação química ${ }^{6-10}$ dos componentes fluorescentes do compósito ou por modificações nas características morfológicas superficiais do compósito $^{33-38}$, o que afeta os índices de reflexão/refração de luz ${ }^{6}$.

Embora existam estudos que avaliem a ação de agentes químicos sobre algumas das propriedades dos compósitos, nenhum examina o efeito dos agentes clareadores na fluorescência dos compósitos. Portanto, mais pesquisas são necessárias para comparar os resultados obtidos neste estudo.

\section{Conclusão}

Os resultados permitem concluir que os compósitos, dependendo de sua composição química, podem ter a intensidade de fluorescência alterada pelos agentes clareadores.

\section{Abstract}

Objective: the aim of this study was to evaluate the influence of different concentrations of carbamide peroxide $(C P)$ bleaching agents on the fluorescence of three composites. Methods: twenty-seven specimens were made and divided into 9 groups $(n=3)$, which were stored in deionized water, exposed to $10 \% \mathrm{CP}$ for 6 hours/day and 22\% CP for 1 hour/day, for 14 days. Then, fluorescence measurements were taken in a spectrophotometer. The fluorescence intensity values obtained were submitted to the Shapiro-Wilk, Levene, and Games-Howell tests $(p<0.05)$. Results: the mean fluorescence intensity for the control groups of Esthet- $X$ and Opallis composites showed no statistically significant differences. However, the composite Charisma showed statistically different fluorescence intensity from the other composites. After exposed to the different bleaching agents, only Charisma composite exposed to $22 \%$ $C P$ showed statistically significant changes, increasing its fluorescence. Conclusion: fluorescence intensity may be affected by the action of carbamide peroxide bleaching agents, depending on its concentration and the composite characteristics.

Keywords: Resin composite. Fluorescence. Bleaching agents. 


\section{Referências}

1. Janda R, Roulet JF, Kaminsky M, Steffin G, Latta M. Color stability of resin matrix restorative materials as a function of the method of light activation. Eur J Oral Sci 2004; 112:280-5.

2. Arens DE. The role of bleaching in esthetic. Dent Clin North Am 1989; 33:319-37.

3. Lim YK, Lee YK. Fluorescent emission of varied shades of resin composite. Dent Mater 2007; 23:1262-8.

4. Takahashi MK, Vieira S, Rachaed RN, Almeida JB, Aguiar M, de Souza EM. Fluorescence intensity of resin composites and dental tissues before and after accelerated aging: a comparative study. Oper Dent 2008; 33(2):189-95.

5. Lee YK, Lu H, Powers JM. Fluorescence of layered resin composites. J Esthet Restor Dent 2005; 37(2):93-100.

6. Masotti AS, Onófrio AB, Conceição EN, Spohr AM. Uv- vis spectrotometric direct transmittance analysis of composites resin. Dent Mater 2007; 23:724-30.

7. Lee YK, Kim SH, Powers JM. Changes in translucency of resin composites after storange in salivary esterase. J Esthet Restor Dent 2005; 17(5):293-9.

8. Campbell PM, Johnston WM, O'brien WJ. Light scattering and gloss of an experimental quartz-filled composite. J Dent Res 1986; 65(6):892-4.

9. Taira M, Okazaki M, Takahashi J. Studies on optical properties of two commercial visible-light-cured composite resins by diffuse reflectance measurements. J Oral Rehabil 1999; 26(4):329-37

10. Wozniak WT, Fan PL, Mcgill S, Moser JB, Stanford JW. Color comparisons of composite resins of various shade designations. Dent Mater 1985; 1(4):121-3.

11. Cattaruzza M. Odontoiatria conservativa restauri adesivi diretti fondamenti sul colore e sue applicazioni. Itália: Acme; 2002.

12. Nassau k. Color for science, art and technology. Lebanon (NJ): Elsevier; 1998.

13. Stephen JC, Ahmad K. Light dynamic properties of a synthetic, low-fusing, quartz glass-ceramic material. Pract Proced Aesthet Dent 2003; 15:49-56.

14. Lee YK, Lu H, Powers JM. Changes in opalescence and fluorescence properties of resin composites after accelerated aging Dent Mater 2006; 22:653-60.

15. Magne P, Belser U. Bonded porcelain restorations in anterior dentition: a biomimetic approach. Chicago (ILL): Quintessence; 2003.

16. Monsenego G, Burdarion G, Clerjaud B. Fluorescence of dental porcelain. J Prostthet Dent 1993; 69(1):106-13.

17. Lee YK, Powers JM. Color difference of four esthetic restorative materials by the illuminant. Am J Dent 2005; 18(5):35963.

18. Lee YK, Powers JM. Metameric effect between resin composite and dentin. Dent Mater 2005; 21(10):971-6.

19. Dietshi D. Layering concepts in anterior composite restorations. J Adhes Dent 2001; 3(1):71-80.

20. Ecker GA, Moser JB, Wosniak WT, Brinsden GI. Effect of repeated firing on fluorescence of porcelain-fused-tometal porcelains. J Prosthet Dent 1985; 54(2):207-14.

21. Peplinsk DR, Wosniak WT, Moser JB. Spectral studies of new lunimophors of dental porcelain. J Dent Res 1980; 59(9):1501-6.

22. Wosniak WT, Moore BK. Luminescence spectra of dental porcelains. J Dent Res 1978; 57(11-12):971-7.
23. Baran GR, O'brian WJ, Tien TY. Colored emission of rare earth ions in potassium feldspar glass. J Dent Res 1977; 56(11):1323-9

24. Rüttermann ST, Ritter J, Raab WH, Bayer R, Janda R. Laser-induced fluorescence to discriminate between a dental composite resin and tooth. Dent Mater 2007; 23:1390-6.

25. Swift Junior EJ, Perdigão J. Effects of bleaching on teeth and restorations. Compendium. 1998; 19:815-20.

26. Costa JB. McPharlin R, Paravina RD, Ferracane JL. Comparison of at-home and in-office tooth whitening using novel shade guide. Oper Dent 2010; 35:381-8.

27. Turker SB, Biskin T. Effect of three bleaching agents on the surface properties of three different esthetic restorative materials. J Prosthet Dent 2003; 89:466-73.

28. Polydorou O, Beiter J, Köning A, Hellwig E, Kümmerer K. Effect of bleaching on the elution of monomers from modern dental composite materials. Dent Mater 2009; 25:254-60.

29. Haywood VB, Heymann HO. Nightguard vital bleaching: How safe is it? Quintessence Int 1991; 22:516-23.

30. Williams HA, Rueggeberg FA, Meister LW. Bleaching the natural dentition to match the color of existing restorations: case reports. Quintessence Int. 1992; 23:673-7.

31. Haywood VB, Heymann HO. Nightguard vital bleaching. Quintessence Int 1989; 20:173-6.

32. Travassos AC, Rocha Gomes Torres C, Borges AB, Barcellos DC. In vitro assessment of chemical activation efficiency durin in-office dental bleaching. Oper Dent 2010; 35:287-94.

33. ISO 7491. Determination of colour stability. 2 ed. Geneve: Dent Mater; 2000.

34. Lee J, Grimaudo NJ, Shen C. Bleaching effects on resin reinforced light-cured glass ionomer. J Dent Res 1999; 78:318.

35. Kilimitzoglou D, Wolff MS. The surface roughness of a microfilm and hibrid composite after exposure to carbamide peroxide. J Dent Res 2000; 79:277.

36. Pimlott JFL, Scott DA. Bleaching gels: the surface effects on composite resin restorations. J Dent Res 1995; 74:245.

37. Robertello JJ, Meares WA, Gunsolley JC, Baughan LW. Effect of peroxide bleaches on fluoride release of dental materials. Am J Dent 1997; 10:264-7.

38. Wolff MS, Joseph J. Determination of the effect of carbamide peroxide bleach on the surface roughness of fixed prosthodontic cements. J Dent Res 1998; 77:1022.

39. Yu BIN, Lee YK. Differences in color, translucency and fluorescence between flowable and universal resin composites. J Dent 2008; 36:840-6.

40. Reis RSA, Casemiro LA, Carlino GV, Lins EC, Kurachi C, Bagnato VS, et al. Evaluation of fluorescence of dental composites using contrast ratios to adjacent tooth structure: A pilot study. J Esthet Restor Dent 2007; 19:199-207.

Endereço para correspondência:

Mariana De Carlo Bello

Universidade Federal de Santa Maria

Rua Av. Medianeira, 1688/802

97060-002 Santa Maria - RS

Fone: (55) 9159-5503

E-mails: maridcbello@yahoo.com.bre

marianabelloendo@gmail.com

Recebido: 02/01/2013. Aceito: 08/05/2013. 